Text: 200 words

Abstract: 1,403 words

Tables: 3

\title{
Concurrent antipsychotic use in older adults treated with antidepressants in Asia
}

Running head: Antipsychotics in older adults

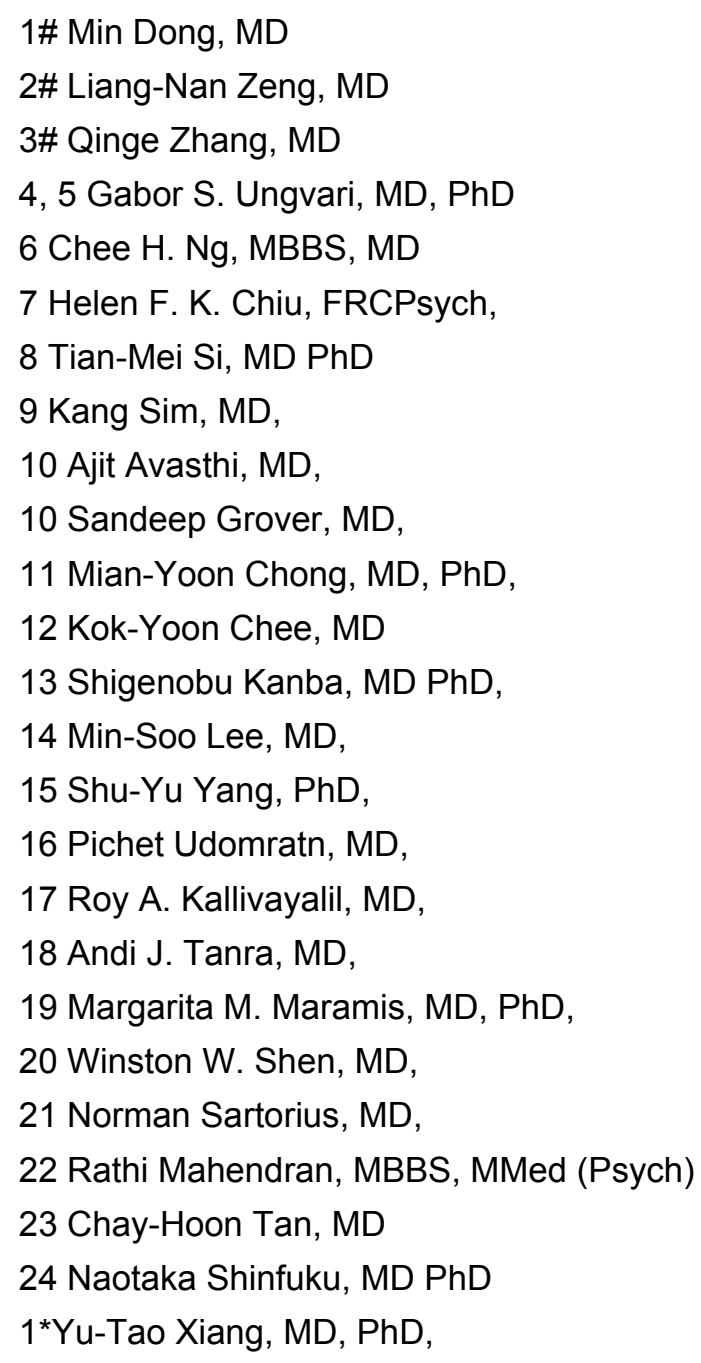

1. Unit of Psychiatry, Faculty of Health Sciences, University of Macau, Macao SAR, China;

2. The Affiliated Hospital of Southwest Medical University, Luzhou, China;

This is the author manuscript accepted for publication and has undergone full peer review but has not been through the copyediting, typesetting, pagination and proofreading process, which may lead to differences between this version and the Version of Record. Please cite this article as doi: $10.1111 /$ psyg.12416

This article is protected by copyright. All rights reserved. 
3. The National Clinical Research Center for Mental Disorders, China \&Center of Depression, Beijing Institute for Brain Disorders \& Mood Disorders Center, Beijing Anding Hospital, Capital Medical University, Beijing, China

4. The University of Notre Dame Australia / Marian Centre, Perth, Australia

5. Graylands Hospital, Perth, Australia

6. Department of Psychiatry, University of Melbourne, Melbourne, Victoria, Australia

7. Department of Psychiatry, Chinese University of Hong Kong, Hong Kong, China

8. Peking University Institute of Mental Health (the sixth Hospital) \& National Clinical Research Center for Mental Disorders \& the key Laboratory of Mental Health, Ministry of Health (Peking University), Beijing, China

9. Institute of Mental Health, Buangkok View, Buangkok Green Medical Park, Singapore

10. Department of Psychiatry, Post Graduate Institute of Medical Education and Research (PGIMER), Chandigarh, India

11. Department of Psychiatry, Kaohsiung Chang Gung Memorial Hospital-Kaohsiung Medical Center and School of Medicine, Chang Gung University, Taiwan

12. Department of Psychiatry \& Mental Health, Tunku Abdul Rahman Institute of Neurosciences, Kuala Lumpur Hospital, Kuala Lumpur, Malaysia

13. Department of Neuropsychiatry, Kyushu University, Fukuoka, Japan

14. Department of Psychiatry, College of Medicine, Korea University, Seoul, Korea

15. Department of Pharmacy, Taipei City Hospital, Taipei, Taiwan

16. Department of Psychiatry, Faculty of Medicine, Prince of Songkla University, Songkhla, Thailand

17. Department of Psychiatry, Pushpagiri Institute of Medical Sciences, Thiruvalla, India

18. Department of Psychiatry, Hasanuddin University Faculty of Medicine, Makassar, Sulawesi Selatan, Indonesia

19. Dr. Soetomo Hospital - Faculty of Medicine, Airlangga University, Jawa Timur, Indonesia

20. Departments of Psychiatry, TMU-Wan Fang Medical Center and School of Medicine, Taipei Medical University, Taiwan

21. Association for the Improvement of Mental Health Programmes, Geneva, Switzerland

22. Department of Psychological Medicine, National University of Singapore, Singapore

23. Department of Pharmacology, National University of Singapore, Singapore

24. International Center for Medical Research, Kobe University School of Medicine, Kobe, Japan

\# These authors contributed equally to this work.

*Address correspondence to Dr. Yu-Tao Xiang, 3/F, Building E12, Faculty of Health Sciences, University of Macau, Avenida da Universidade, Taipa, Macau SAR, China. Fax: +853-2288-2314; Phone: +853-8822-4223; E-mail: xyutly@gmail.com

This article is protected by copyright. All rights reserved. 


\section{Abstract}

Background: Depressive disorders are common in old age. Antipsychotics (APs) are often used as an adjunctive treatment with antidepressants (ADs) in this population but its patterns of use in Asia are not known. This study explored the rate of combination of APs and ADs in older adult psychiatric patients in Asia.

Methods: This is a secondary analysis of the database of a multicenter study which recorded participants' basic demographical and clinical data in standardized format in ten Asian countries and territories. The data were analyzed using univariate and multivariate logistic regression analyses.

Results: A total of 955 older adult psychiatric in- and outpatients were included in this study. The proportion of concurrent AP and AD use was $32.0 \%$, ranging from $23.3 \%$ in Korea to $44.0 \%$ in Taiwan. Multivariate logistic regression analysis 
found that younger age, inpatient status and diagnosis of schizophrenia were significantly related to a higher proportion of concurrent use of APs and ADs.

Conclusion: Around a third of older adult psychiatric patients had concurrent AP and $A D$ use in the Asian countries/regions surveyed. Considering the uncertain effectiveness and questionable safety of the APs and ADs combination in this patient population, this type of polypharmacy should be used cautiously.

Key words adjunctive treatment, antidepressants, antipsychotics, Asia, older adults 


\section{Introduction}

Depressive disorders are frequent in older adults. For example, one survey found that the prevalence of major depression was up to $16 \%$ in old people living in private households or institutions. ${ }^{1}$ Another study reported that the prevalence of major depressive disorder, minor depression and clinically relevant depressive symptoms in old people living in the community were $1.8 \%, 9.8 \%$ and $13.5 \%$, respectively. ${ }^{2}$ Compared to younger adults, older adults suffering from depression have an increased risk of physical and psychological comorbidities, more disability and social isolation, ${ }^{3-6}$ greater economic cost, ${ }^{7,8}$ and higher mortality. ${ }^{1,9}$

Psychotropic medications are prescribed for old people up to 7-18 times more frequently than for middle-aged adults. ${ }^{10}$ Of the psychotropic medications, antidepressants (ADs) are one of the most widely prescribed ones. ${ }^{11,12}$ For example, one study found that $51.8 \%$ of nursing homes residents suffered from depression, of whom $82.8 \%$ received $A D s .{ }^{13}$ Antipsychotics (APs), such as aripiprazole, quetiapine and olanzapine, are often used augmenting ADs for depression. ${ }^{14}$ Over half of older adults who received ADs are also prescribed other psychotropic drugs, particularly benzodiazepines (BZDs) and APs. ${ }^{15}$ Compared to younger adults, due to their poorer general health status and age-related physiological changes, older adults are more likely to experience 
medication-induced adverse events. ${ }^{16,17}$ Therefore, polypharmacy with psychotropic medications in older adults, if indicated at all, should be prescribed cautiously.

Regular surveys of prescription patterns are useful to examine the appropriateness of pharmacotherapy. ${ }^{18}$ Although APs and ADs combinations are often used, the frequency of such co-prescription patterns are unknown in older adult psychiatric patients in Asia. This study set out to examine the concurrent use of APs and ADs in older adult psychiatric patients in several Asian countries and territories in, and explore its independent demographic and clinical correlates.

\section{Methods}

Study design and sample

The Research on Asian Psychotropic Prescription Patterns for Antidepressants (REAP-AD) project is an international, multicenter survey on the use of $A D s,{ }^{19}$ which was conducted between March and June 2013 in 42 centers and hospitals in ten Asian territories and countries, including China, Malaysia, Hong Kong, India, Indonesia, Japan, Thailand, Korea, Singapore and Taiwan. Patients with any mental disorder treated with ADs on the day of data collection were consecutively screened and enrolled in the survey. The data were collected with 
a standardized protocol in all participating hospitals. Patients who were eligible for the study were aged 50 years or above and were either in- or outpatients. In many Asian countries, patients aged 50 years or older are defined as 'old people'. This cut-off is in line with some other studies. ${ }^{20-22}$ The study protocol was approved by the Institutional Review Boards at each participating center and hospital. When the survey involved retrospective anonymous medical chart review, informed consent was waived. However, when patients were interviewed, they provided written informed consent.

\section{Assessment}

Patients' demographical and clinical data were retrieved by reviewing medical records, or during a clinical interview supplemented by a review of medical records. Diagnoses were established according to $\mathrm{ICD}-10^{23}$ or DSM-IV. ${ }^{24}$ For the sake of comparison in the statistical analysis, doses of ADs were transformed into imipramine equivalent (IMI-eq) doses. ${ }^{25}$

\section{Statistics}

Data analyses were performed with the SPSS statistical package, Version 20. The demographical and clinical data were compared between patients treated with APs plus ADs and on ADs only with Mann-Whitney U-test, independent sample 
$t$-test or $x^{2}$ test, if applicable. Independent associations between demographical and clinical characteristics (independent variables) and the combination of APs and ADs (dependent variable) were explored with binary logistic regression analysis. The variables that significantly differed in univariate analysis were entered as independent variables, and the combination of APs and ADs was the dependent variable. Statistical significance was set at 0.05 (two-sided).

\section{Results}

A total of 955 older adult patients who received antidepressants were enrolled in the study. The rate of combination of APs and ADs in the whole sample was $32.0 \%$ ranging from $23.3 \%$ in Korea to $44.0 \%$ in Taiwan (Table 1 ). Table 2 shows the demographic and clinical data for the whole sample and separately for the ADs and the combination groups. In the whole sample, the mean age was 62.6 years and 375 patients (39.3\%) were men; the proportion of mood disorders, anxiety disorders, schizophrenia and other diagnoses was $70.3 \%, 13.6 \%, 8.3 \%$ and 7.9\%, respectively. The mean dose of ADs in IMI-eq was $131.2 \mathrm{mg} / \mathrm{day}$.

Concurrent APs and ADs use was significantly associated with younger age, male gender, less number of ADs, inpatient treatment, in psychiatric or public hospitals, more frequent use of mood stabilizers (MS) and BZDs, and psychiatric diagnoses (Table 2). Binary logistic regression analyses found that concurrent 
APs and ADs prescription was independently related to younger age, inpatient treatment and diagnosis of schizophrenia, anxiety and other mental disorders (Table 3).

\section{Discussion}

This was the first survey of the pattern of concurrent use of APs and ADs in older adult psychiatric patients in Asia. The proportion of concurrent prescription was $32.0 \%$ in the whole sample but it varied markedly across countries/territories, with the highest in Taiwan (44.0\%) and lowest in Korea (23.3\%). These figures are much higher than the corresponding ones in the USA (13.9\%) and Europe $(12.3 \%) .{ }^{26}$ The discrepancy across study sites could be related to the diversity of socio-cultural factors, local clinical practices, healthcare polices, medication cost, and insurance coverage. ${ }^{27}$ For example, there is a widely held view in Asia that combination of medications of different pharmacological activities has better efficacy in clinical practice. ${ }^{28}$ In addition, the co-existence of psychotic and depressive symptoms occurring in various psychiatric disorders are frequent in elderly patients, increasing the likelihood of concurrent use of APs and ADs. As the risk of side effects of psychotropic drugs may increase due to the age-related changes in pharmacokinetic and pharmacodynamics responses in older 
patients, ${ }^{17}$ the safety of APs and ADs combination should be taken into consideration in clinical practice.

Concurrent use of APs and ADs was associated with psychiatric diagnoses (particularly schizophrenia), younger age and inpatient treatment in this study. ADs were often prescribed in schizophrenia for negative and depressive symptoms and even lessening cognitive impairment. ${ }^{29}$ Negative and depressive symptoms improve in around a third of schizophrenia patients receiving ADs 30,31 and adjunctive ADs. ${ }^{32-34}$ This may be related to the effect of ADs in modifying serotonergic (5-HT) dysfunction that is thought to be involved in the pathophysiology of psychotic symptoms. ${ }^{14,35,36}$

Although $A D$ monotherapy has been recommended in treating depressive disorders, ${ }^{37}$ adjunctive APs are often used as an augmentation strategy for treatment-resistant depression. ${ }^{38}$ Second generation antipsychotics (SGAs) are frequently co-prescribed with ADs ${ }^{39,40}$ given that SGAs improve depressive symptoms $^{42}$ by enhancing monoaminergic transmission ${ }^{14,41}$. A meta-analysis demonstrated that adjunctive SGAs have significant effects on the severity of major depression, resulting in improved quality of life and less functional deficit. $^{43}$

In this survey, inpatients were more likely to be treated with APs and ADs combination, probably due to the more severe psychiatric symptoms. ${ }^{44}$ Previous 
studies in the US and Europe found that depressed patients prescribed with APS present with more severe comorbid psychotic symptoms. ${ }^{26}$ The finding that younger age was associated with concurrent APs and ADs use is perhaps due to the better tolerance of polypharmacy in younger age. Conversely, the higher risk of medication-induced adverse events in older patients may discourage psychiatrists to prescribe combinations of psychotropic medications.

Several limitations of the study should be acknowledged. First, the sample size in several countries/territories was small, therefore analyses could not be performed separately in each study site. Second, as only 10 Asian countries/territories were included in the study, the findings are not representative of the whole Asian patient population. Third, due to the cross-sectional study the causality between variables could not be explored. Fourth, due to logistical reasons the severity of depressive and psychotic symptoms was not measured, hence their associations with prescription patterns could not be analyzed. Fifth, the study mainly focused on prescription of ADs in psychiatric hospitals or psychiatric units at general hospitals. Patients with other psychiatric and medical diagnoses treated with ADs, such as dementia or other neuropsychiatric disorders, rarely treated in psychiatric hospitals/units in most Asian countries, thus they were not covered in this study. Finally, several relevant factors of prescription patterns, such as cost of treatment, were not recorded. 
In conclusion, around a third of older adult psychiatric patients in ten Asian countries and territories received concurrent ADs and APs. Given the increased age-related risks of psychotropic medication-induced side effects, the combination of ADs and APs should be used with caution in this population.

\section{Acknowledgements}

This work was supported by the Taipei City Hospital (10201-62-077), Taipei, Taiwan and the University of Macau (MYRG2015-00230-FHS; MYRG2016-00005-FHS). The authors would like to thank all clinicians involved in the REAP-AD project.

\section{Disclosure statement}

We declare that the authors have no competing interests related to this study. 


\section{References}

1. Djernes JK. Prevalence and predictors of depression in populations of elderly: a review. Acta Psychiatr Scand 2006; 113: 372-387.

2. Beekman AT, Copeland JR, Prince MJ. Review of community prevalence of depression in later life. Br J Psychiatry 1999; 174: 307-311.

3. Valkanova V, Ebmeier KP. Vascular risk factors and depression in later life: a systematic review and meta-analysis. Biol Psychiatry 2013; 73: 406-413.

4. Gansler DA, Suvak M, Arean P, Alexopoulos GS. Role of executive dysfunction and dysexecutive behavior in late-life depression and disability. Am J Geriatr Psychiatry 2015; 23: 1038-1045.

5. Grossberg GT, Beck D, Zaidi SNY. Rapid depression assessment in geriatric patients. Clin Geriatr Med 2017; 33: 383-391.

6. Fiske A, Wetherell JL, Gatz M. Depression in older adults. Annual Rev Clin. Psychol 2009; 5: 363-389.

7. Luppa M, Heinrich S, Matschinger $H$, et al. Direct costs associated with depression in old age in Germany. J Affect Disord 2008; 105: 195-204.

8. Blazer DG. Depression in late life: review and commentary. J Gerontology Series A: Biological Sciences and Medical Sciences 2003; 58: M249-M265.

9. Wilson K, Mottram PG, Sivananthan A, Nightingale A. Antidepressants versus placebo for the depressed elderly. The Cochrane Library 2001. 
10. Voyer $P$, Martin LS. Improving geriatric mental health nursing care: making a case for going beyond psychotropic medications. Int. JMental Health Nursing 2003; 12: 11-21.

11. Aarts N, Noordam R, Hofman A, Tiemeier H, Stricker BH, Visser LE. Utilization patterns of antidepressants between 1991 and 2011 in a population-based cohort of middle-aged and elderly. Eur Psychiatry 2014; 29: 365-370.

12. Parabiaghi A, Franchi C, Tettamanti M, et al. Antidepressants utilization among elderly in Lombardy from 2000 to 2007: dispensing trends and appropriateness. Eur J Clin Pharmacol 2011; 67: 1077.

13. Gaboda D, Lucas J, Siegel M, Kalay E, Crystal S. No longer undertreated? Depression diagnosis and antidepressant therapy in elderly long-stay nursing home residents, 1999 to 2007. J Am Geriatr Soc 2011; 59: 673-680.

14. Han $C$, Wang S-M, Kato $M$, et al. Second-generation antipsychotics in the treatment of major depressive disorder: current evidence. Expert Review of Neurotherapeutics 2013; 13: 851-870.

15. Fulone I, Lopes LC. Potentially inappropriate prescriptions for elderly people taking antidepressant: comparative tools. BMC Geriatrics 2017; 17: 278.

16. Mangoni $\mathrm{AA}$, Jackson $\mathrm{SH}$. Age-related changes in pharmacokinetics and pharmacodynamics: basic principles and practical applications. $\mathrm{Br} \mathrm{J}$ Clin Pharmacol 2004; 57: 6-14. 
17. Uchida H, Mamo DC, Mulsant BH, Pollock BG, Kapur S. Increased antipsychotic sensitivity in elderly patients: evidence and mechanisms. The J Clin Psychiatry 2009; 70: 397-405.

18. Ungvari GS, Chow LY, Chiu HF, Ng FS, Leung T. Modifying psychotropic drug prescription patterns: a follow-up survey. Psychiat Clin Neurosci 1997; 51: 309-314.

19. Zhong XM, Wang F, Zhang Q, et al. Concurrent benzodiazepine use in older adults treated with antidepressants in Asia. Int Psychogeriatr 2017; 1-7.

20. Cole MG, Dendukuri N. Risk factors for depression among elderly community subjects: a systematic review and meta-analysis. Am J Psychiatry 2003; 160: 1147-1156.

21. Dassori AM, Copeland LA, Zeber JE, Miller AL. Factors in second-generation antipsychotic switching patterns in a national sample of older veterans with schizophrenia. Psychiatr Serv 2011; 62: 47-53.

22. Duberstein PR, Conwell Y, Seidlitz L, Denning DG, Cox C, Caine ED. Personality traits and suicidal behavior and ideation in depressed inpatients 50 years of age and older. J Gerontology Series B 2000; 55: P18-P26.

23.W.H.O. The ICD-10 Classification of Mental and Behavioural Disorders: Clinical Descriptions and Diagnostic Guidelines. Geneva: World Health Organization; 1992. inadequate details, 
24. APA. Diagnostic and Statistical Manual of Mental Disorders 4th edition. American Psychiatric Association, Washington, 1994.

25. Rajaratnam K, Xiang YT, Tripathi A, et al. Factors associated with antidepressant dosing in Asia: findings from the Research on Asian Psychotropic Prescription Study. J Clin Psychopharmacol 2016; 36: 716-719.

26. McIntyre RS, Weiller E. Real-world determinants of adjunctive antipsychotic prescribing for patients with major depressive disorder and inadequate response to antidepressants: a case review study. Adv Ther 2015; 32: 429-444.

27. Xiang YT, Ungvari GS, Wang CY, et al. Adjunctive antidepressant prescriptions for hospitalized patients with schizophrenia in Asia (2001-2009). Asia-Pacific Psychiatry 2013; 5. doi: 10.1111/j.1758-5872.2012.00231.x.

28. Phillips MR, Lu SH, Wang RW. Economic reforms and the acute inpatient care of patients with schizophrenia: the Chinese experience. Am J Psychiatry 1997; 154: $1228-1234$.

29. Mao Y-M, Zhang M-D. Augmentation with antidepressants in schizophrenia treatment: benefit or risk. Neuropsychiatric Disease and Treatment 2015; 11: 701.

30. Himelhoch S, Slade E, Kreyenbuhl J, Medoff D, Brown C, Dixon L. Antidepressant prescribing patterns among VA patients with schizophrenia. Schizophr Res 2012; 136: 32-35. 
31. Acquaviva E, Gasquet I, Falissard B. Psychotropic combination in schizophrenia. Eur J Clin Pharmacol 2005; 61: 855-861.

32. Galling B, Vernon JA, Pagsberg AK, et al. Efficacy and safety of antidepressant augmentation of continued antipsychotic treatment in patients with schizophrenia. Acta Psychiatr Scand 2018; 137: 187-205.

33. Helfer B, Samara MT, Huhn M, et al. Efficacy and safety of antidepressants added to antipsychotics for schizophrenia: a systematic review and meta-analysis. Am J Psychiatry 2016; 173: 876-886.

34. Rummel C, Kissling W, Leucht S. Antidepressants for the negative symptoms of schizophrenia. Cochrane Database Syst Rev 2006; 3: Cd005581.

35. Meltzer HY. Serotonergic mechanisms as targets for existing and novel antipsychotics. Handbook of Experimental Pharmacology 2012; 212: 87-124.

36. Meltzer $\mathrm{H}$, Massey $\mathrm{B}$. The role of serotonin receptors in the action of atypical antipsychotic drugs. Current Opinion in Pharmacology 2011; 11: 59-67.

37. Cosgrove L, Shaughnessy AF, Peters SM, Lexchin JR, Bursztajn H, Bero L. Conflicts of interest and the presence of methodologists on guideline development panels: a cross-sectional study of clinical practice guidelines for major depressive disorder. Psychother Psychosom 2017; 86: 168-170.

38. Dold M, Kasper S. Evidence-based pharmacotherapy of treatment-resistant unipolar depression. IntJ Psychiatry in Clin Practice 2017; 21: 13-23. 
39. Berman RM, Fava M, Thase $M E$, et al. Aripiprazole augmentation in major depressive disorder: a double-blind, placebo-controlled study in patients with inadequate response to antidepressants. CNS Spectrums 2009; 14: 197-206. 40. Marcus RN, McQuade RD, Carson WH, et al. The efficacy and safety of aripiprazole as adjunctive therapy in major depressive disorder: a second multicenter, randomized, double-blind, placebo-controlled study. J Clin Psychopharmacol 2008; 28: 156-165.

41. Blier P. Rational site-directed pharmacotherapy for major depressive disorder. Int J Neuropsychopharmacol 2014; 17: 997-1008.

42. Rogoz Z. Combined treatment with atypical antipsychotics and antidepressants in treatment-resistant depression: preclinical and clinical efficacy. Pharmacol Rep 2013; 65: 1535-1544.

43. Spielmans GI, Berman MI, Linardatos E, Rosenlicht NZ, Perry A, Tsai AC. Adjunctive atypical antipsychotic treatment for major depressive disorder: a meta-analysis of depression, quality of life, and safety outcomes. PLoS Medicine 2013; 10: e1001403.

44. Möller H-J, Seemüller F, Schennach-Wolff R, Stübner S, Rüther E, Grohmann R. History, background, concepts and current use of comedication and polypharmacy in psychiatry. Int J Neuropsychopharmacol 2014; 17: 983-996. 


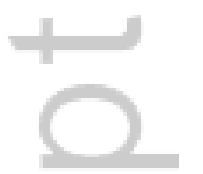

4 
Table 1. Prescription of psychotropic medication for olderadult psychiatric patients by country/territory

\begin{tabular}{|c|c|c|c|c|c|c|c|c|c|c|c|c|c|c|c|c|c|c|c|c|c|c|c|}
\hline \multirow[t]{2}{*}{ Country/territory } & \multicolumn{2}{|c|}{$\begin{array}{c}\text { China } \\
(n=158)\end{array}$} & \multicolumn{2}{|c|}{$\begin{array}{c}\text { Hong Kong } \\
(\mathrm{n}=39)\end{array}$} & \multicolumn{2}{|c|}{$\begin{array}{c}\text { Japan } \\
(n=119)\end{array}$} & \multicolumn{2}{|c|}{$\begin{array}{c}\text { RO Korea } \\
(n=150)\end{array}$} & \multicolumn{2}{|c|}{$\begin{array}{c}\text { Singapore } \\
(\mathrm{n}=48)\end{array}$} & \multicolumn{2}{|c|}{$\begin{array}{l}\text { Taiwan } \\
(n=109)\end{array}$} & \multicolumn{2}{|c|}{$\begin{array}{c}\text { India } \\
(n=63)\end{array}$} & \multicolumn{2}{|c|}{$\begin{array}{c}\text { Malaysia } \\
(n=67)\end{array}$} & \multicolumn{2}{|c|}{$\begin{array}{c}\text { Thailand } \\
(n=128)\end{array}$} & \multicolumn{2}{|c|}{$\begin{array}{c}\text { Indonesia } \\
\quad(n=74)\end{array}$} & \multicolumn{2}{|c|}{$\begin{array}{l}\text { Overall } \\
(n=955)\end{array}$} & \multirow{2}{*}{$\begin{array}{r}\mathrm{AP}=\text { antipsy } \\
\text { chotics; } \\
\mathrm{BZD}=\text { benzo }\end{array}$} \\
\hline & $\mathrm{n}$ & $\%$ & $\mathrm{n}$ & $\%$ & $\mathrm{n}$ & $\%$ & $\mathrm{n}$ & $\%$ & $\mathrm{n}$ & $\%$ & $\mathrm{n}$ & $\%$ & $\mathrm{n}$ & $\%$ & $\mathrm{n}$ & $\%$ & $\mathrm{n}$ & $\%$ & $\mathrm{n}$ & $\%$ & $\mathrm{n}$ & $\%$ & \\
\hline APs & 51 & 32.3 & 17 & 43.6 & 40 & 33.6 & 35 & 23.3 & 17 & 35.4 & 48 & 44.0 & 16 & 25.4 & 20 & 29.9 & 30 & 23.4 & 32 & 43.2 & 306 & 32.0 & \\
\hline TCAs & 6 & 3.8 & 3 & 7.7 & 15 & 12.6 & 18 & 12 & 1 & 2.1 & 8 & 7.3 & 7 & 11.1 & 1 & 1.5 & 33 & 25.8 & 7 & 9.5 & 99 & 10.4 & \\
\hline Tetracyclics & 0 & 0 & 0 & 0 & 7 & 5.9 & 0 & 0 & 0 & 0 & 0 & 0 & 0 & 0 & 1 & 1.5 & 19 & 14.8 & 0 & 0 & 27 & 2.8 & $\mathrm{NaSSA}=$ nor \\
\hline SSRIs & 103 & 65.2 & 21 & 53.8 & 52 & 43.7 & 101 & 67.3 & 30 & 62.5 & 57 & 52.3 & 44 & 69.8 & 47 & 70.1 & 71 & 55.5 & 67 & 90.5 & 593 & 62.1 & adrenergic \\
\hline SNRIs & 42 & 26.6 & 7 & 17.9 & 24 & 20.2 & 35 & 23.3 & 3 & 6.3 & 22 & 20.2 & 10 & 15.9 & 4 & 6 & 8 & 6.3 & 0 & 0 & 155 & 16.2 & and specific \\
\hline NaSSAs & 31 & 19.6 & 6 & 15.4 & 40 & 33.6 & 36 & 24 & 12 & 25 & 11 & 10.1 & 6 & 9.5 & 13 & 19.4 & 8 & 6.3 & 0 & 0 & 163 & 17.1 & \\
\hline Other drugs & 12 & 7.6 & 6 & 15.4 & 16 & 13.4 & 39 & 26 & 5 & 10.4 & 23 & 21.1 & 2 & 3.2 & 2 & 3 & 22 & 17.2 & 0 & 0 & 127 & 13.3 & \\
\hline BZDs & 64 & 40.5 & 19 & 48.7 & 71 & 59.7 & 40 & 26.7 & 16 & 33.3 & 76 & 69.7 & 18 & 28.6 & 31 & 46.3 & 50 & 39.1 & 38 & 51.4 & 423 & 44.3 & $\mathrm{TCA}=$ tricyc \\
\hline MS & 5 & 3.2 & 1 & 2.6 & 15 & 12.6 & 5 & 3.3 & 4 & 8.3 & 11 & 10.1 & 6 & 9.5 & 0 & 0.0 & 12 & 9.4 & 4 & 5.4 & 63 & 6.6 & lic \\
\hline
\end{tabular}

nt; SSRI=selective serotonin reuptake inhibitor; SNRI=serotonin/norepinephrine reuptake inhibitor 
Table 2. Basic demographic and clinical characteristics of the study sample

\begin{tabular}{|c|c|c|c|c|c|c|c|c|c|}
\hline & \multicolumn{2}{|c|}{$\begin{array}{c}\text { The whole } \\
\text { sample } \\
(\mathrm{n}=955)\end{array}$} & \multicolumn{2}{|c|}{$\begin{array}{l}\text { No APs } \\
(\mathrm{n}=649)\end{array}$} & \multicolumn{2}{|c|}{$\begin{array}{c}\text { On APs } \\
(\mathrm{n}=306)\end{array}$} & \multicolumn{3}{|c|}{ Statistics } \\
\hline & Mean & SD & Mean & SD & Mean & SD & $t / z$ & $d f$ & $P$ \\
\hline Age (years) & 62.6 & 9.5 & 63.3 & 9.7 & 60.9 & 8.7 & 3.7 & 953 & $<0.001$ \\
\hline AD dose, IMIeq (mg/d) & 131.2 & 112.5 & 126.5 & 109.1 & 141.1 & 118.8 & -1.9 & --- & 0.051 \\
\hline Number of ADs & 1.2 & 0.5 & 1.27 & 0.51 & 1.21 & 0.53 & -2.1 & --- & 0.029 \\
\hline \multirow[t]{2}{*}{ Number of depressive symptoms } & 3.4 & 2.0 & 3.4 & 2.0 & 3.5 & 2.1 & -0.8 & --- & 0.38 \\
\hline & $\mathrm{N}$ & $\%$ & $\mathrm{~N}$ & $\%$ & $\mathrm{~N}$ & $\%$ & $c^{c}$ & $d f$ & $P$ \\
\hline Age (years) & & & & & & & 9.1 & 1 & 0.002 \\
\hline $50-64$ & 615 & 64.4 & 397 & 61.2 & 218 & 71.2 & & & \\
\hline 65 and older & 340 & 35.6 & 252 & 38.8 & 88 & 28.8 & & & \\
\hline Male & 375 & 39.3 & 238 & 36.7 & 137 & 44.8 & 5.7 & 1 & 0.017 \\
\hline Psychiatric hospital & 351 & 36.8 & 201 & 31.0 & 150 & 49.0 & 29.1 & 1 & $<0.001$ \\
\hline Outpatients & 722 & 75.6 & 544 & 83.8 & 178 & 58.2 & 74.1 & 1 & $<0.001$ \\
\hline General hospital psychiatric unit & 687 & 71.9 & 448 & 69.0 & 239 & 78.1 & 8.4 & 1 & 0.004 \\
\hline Country/ territory & & & & & & & 25.2 & 9 & 0.003 \\
\hline Income & & & & & & & 3.1 & 2 & 0.21 \\
\hline High income & 465 & 48.7 & 308 & 47.5 & 157 & 51.3 & & & \\
\hline Upper middle income & 353 & 37.0 & 252 & 38.8 & 101 & 33.0 & & & \\
\hline Lower middle income & 137 & 14.3 & 89 & 13.7 & 48 & 15.7 & & & \\
\hline Major medical conditions & 421 & 44.1 & 281 & 43.3 & 140 & 45.8 & 0.5 & 1 & 0.47 \\
\hline \multicolumn{10}{|l|}{ Use of antidepressants } \\
\hline TCAs & 99 & 10.4 & 75 & 11.6 & 24 & 7.8 & 3.0 & 1 & 0.07 \\
\hline Tetracyclics & 27 & 2.8 & 21 & 3.2 & 6 & 2.0 & 1.2 & 1 & 0.26 \\
\hline SSRIs & 593 & 62.1 & 407 & 62.7 & 186 & 60.8 & 0.3 & 1 & 0.56 \\
\hline SNRIs & 155 & 16.2 & 104 & 16.0 & 51 & 16.7 & 0.06 & 1 & 0.80 \\
\hline NaSSAs & 163 & 17.1 & 109 & 16.8 & 54 & 17.6 & 0.1 & 1 & 0.74 \\
\hline Other ADs & 127 & 13.3 & 85 & 13.1 & 42 & 13.7 & 0.07 & 1 & 0.79 \\
\hline Use of MS & 63 & 6.6 & 31 & 4.8 & 32 & 10.5 & 10.8 & 1 & 0.001 \\
\hline Use of BZDs & 423 & 44.3 & 268 & 41.3 & 155 & 50.7 & 7.3 & 1 & 0.007 \\
\hline Principal psychiatric diagnosis & & & & & & & 93.5 & 3 & $<0.001$ \\
\hline Mood disorders & 671 & 70.3 & 479 & 73.8 & 192 & 62.7 & & & \\
\hline Anxiety disorders & 130 & 13.6 & 109 & 16.8 & 21 & 6.9 & & & \\
\hline Schizophrenia & 79 & 8.3 & 19 & 2.9 & 60 & 19.6 & & & \\
\hline
\end{tabular}




\begin{tabular}{|l|l|l|l|l|l|l|l|l|l|}
\hline Other diagnoses & 75 & 7.9 & 42 & 6.5 & 33 & 10.8 & & & \\
\hline
\end{tabular}

Bolded values: $<0.05 ; \mathrm{AD}=$ antidepressant; $\mathrm{AP}=$ antipsychotic; $\mathrm{BZD}=$ benzodiazepine; $\mathrm{TCA}=$ tricyclic antidepressants; $\mathrm{NaSSA}=$ noradrenergic and specific serotonergic antidepressant; SSRI=selective serotonin reuptake inhibitor; $\mathrm{SNRI}=$ serotonin/norepinephrine reuptake inhibitor; IMI-eq=imipramine-equivalent; MS=mood stabilizer 
Table 3. Independent demographic and clinical correlates of concurrent antipsychotics and antidepressants use

\begin{tabular}{|l|c|c|c|}
\hline Variables & $\boldsymbol{P}$ value & Odds Ratio & $\mathbf{9 5 \%}$ CI \\
\hline Age (years) & $\mathbf{0 . 0 2 6}$ & 0.98 & $0.963-0.998$ \\
\hline Number of ADs & 0.97 & 1.006 & $0.727-1.392$ \\
\hline Male & 0.301 & 0.181 & $0.861-1.619$ \\
\hline Psychiatric hospital & 0.424 & 1.183 & $0.783-1.787$ \\
\hline Outpatients & $<\mathbf{0 . 0 0 1}$ & 0.305 & $0.213-0.438$ \\
\hline General hospital psychiatric unit & 0.307 & 1.309 & $0.781-2.192$ \\
\hline Use of MS & 0.253 & 1.41 & $0.783-2.539$ \\
\hline Use of BZDs & 0.519 & 1.112 & $0.806-1.533$ \\
\hline Principal psychiatric diagnosis & & & \\
\hline Mood disorders & --- & 1 & --- \\
\hline Anxiety disorders & $\mathbf{0 . 0 1}$ & 0.493 & $0.289-0.842$ \\
\hline Schizophrenia & $<\mathbf{0 . 0 0 1}$ & 6.284 & $3.432-11505$ \\
\hline Other diagnoses & $\mathbf{0 . 0 0 4}$ & 2.265 & $1.296-3.957$ \\
\hline Country/territory & & & \\
\hline China & 0.395 & 1 & 0 \\
\hline Hong Kong & 0.271 & 1.586 & $0.698-3.606$ \\
\hline Japan & 0.276 & 1.408 & $0.761-2.609$ \\
\hline South Korea & 0.554 & 1.238 & $0.611-2.509$ \\
\hline Singapore & 0.951 & 1.028 & $0.429-2.463$ \\
\hline Taiwan & 0.367 & 1.360 & $0.698-2.651$ \\
\hline India & 0.325 & 1.456 & $0.689-3.075$ \\
\hline Malaysia & 0.541 & 1.265 & $0.596-2.688$ \\
\hline Thailand & 0.391 & 0.765 & $0.415-1.411$ \\
\hline Indonesia & $\mathbf{0 . 0 3 9}$ & 2.004 & $1.035-3.878$ \\
\hline
\end{tabular}

Bold values: $<0.05$; participating country/territory has been controlled for as a covariate. $A D=$ antidepressants; BZD=benzodiazepine; IMI-eq=imipramine-equivalent; $\mathrm{MS}=$ mood stabilizer; $\mathrm{SGA}=$ second-generation antipsychotic 


\section{University Library}

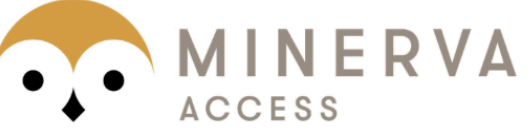

A gateway to Melbourne's research publications

Minerva Access is the Institutional Repository of The University of Melbourne

\section{Author/s:}

Dong, M;Zeng, L-N;Zhang, Q;Ungvari, GS;Ng, CH;Chiu, HFK;Si, T-M;Sim, K;Avasthi, A;Grover, S;Chong, M-Y;Chee, K-Y;Kanba, S;Lee, M-S;Yang, S-Y;Udomratn, P;Kallivayalil, RA;Tanra, AJ;Maramis, MM;Shen, WW;Sartorius, N;Mahendran, R;Tan, C-H;Shinfuku, $\mathrm{N} ;$ Xiang, $\mathrm{Y}-\mathrm{T}$

Title:

Concurrent antipsychotic use in older adults treated with antidepressants in Asia

Date:

2019-07-01

\section{Citation:}

Dong, M., Zeng, L. -N., Zhang, Q., Ungvari, G. S., Ng, C. H., Chiu, H. F. K., Si, T. -M., Sim, K., Avasthi, A., Grover, S., Chong, M. -Y., Chee, K. -Y., Kanba, S., Lee, M. -S., Yang, S. -Y., Udomratn, P., Kallivayalil, R. A., Tanra, A. J., Maramis, M. M. ,... Xiang, Y. -T. (2019). Concurrent antipsychotic use in older adults treated with antidepressants in Asia. PSYCHOGERIATRICS, 19 (4), pp.333-339. https://doi.org/10.1111/psyg.12416.

Persistent Link:

http://hdl.handle.net/11343/285429 